\title{
The Relationship between Supervisor and Subordinate Value Congruence and Role Stress
}

\author{
Kathleen Dale \\ Minnesota State University, Mankato \\ Marilyn L. Fox \\ Minnesota State University, Mankato \\ Christine Brown Mahoney \\ Minnesota State University, Mankato \\ Author's Note
}

Kathleen Dale, Department of Marketing, Minnesota State University, Mankato

Marilyn L. Fox, Department of Marketing, Minnesota State University, Mankato Christine Brown Mahoney, Department of Marketing, Minnesota State University, Mankato

Correspondence concerning this article should be addressed to: Marilyn L. Fox, Department of Management, Morris Hall 150, Minnesota State University, Mankato, Mankato MN 56001; or marilyn.fox@mnsu.edu

\begin{abstract}
This study examined the congruence of values between 96 supervisor and subordinate dyads in a manufacturing organization, as well as the effect that value congruence has on the perceived role stress of the employee. The Comparative Emphasis Scale (CES) was used to measure value congruence on four work values: achievement, honesty, concern, and fairness. The results of the regression analysis found significant support for a negative relationship between value congruence and role stress for the achievement value. In addition, the control variables of years in current position (in current position for ten or more years) of the employee, and the leadership styles of consideration and initiating structure of the supervisors all had significant effects. Results and directions for future research are discussed.
\end{abstract}

Keywords: values, value congruence, stress

\section{Introduction}

The concept of congruence or "fit" between the person and the organization has been well studied and the results indicate that congruence has a positive impact on employees' jobs 
and career satisfaction, commitment, sense of security, and intention to remain with or leave the organization (e.g., Adkins \& Naumann, 2002; Chapman, 1989; Edwards, 1994; Erdogan, Kraimer, \& Liden, 2004; Finegan, 2000; Kristof-Brown, Zimmerman \& Johnson, 2005; Meglino, Ravlin \& Adkins, 1989; Ravlin \& Meglino, 1987; Shea-Van Fossen \& Vredenburgh, 2014). One basic characteristic that is shared by both the individual and the organization is values. Generally speaking, values refer to principles or beliefs of a person or social group in which they have emotional investment. In work situations, Dose (1997) suggests values "are evaluative standards relating to work or the work environment by which individuals discern what is "right" or "wrong" and assess the importance of preferences" (pp. 227-228). Theoretically, congruence between an organization's values or culture and an individual's values is a significant type of person-organization fit because values are enduring beliefs that help develop one's attitudes, justify one's actions and guide behavior (Rokeach, 1973).

Social identity theory suggests that people want to make sense of their environment and often categorize themselves into groups to help fulfill the need to have coordinated social interactions with those that are similar to them. Having value congruence becomes one mechanism that fulfills employee's needs to attach to an organization because other organizational members are similar to them (Schwartz \& Bilsky 1987; Kristof-Brown et al. 2005).

Recently, Gonzalez (2016) collected data from units of a chain of restaurants to examine value congruence in a moderator role. He studied person-organization fit involving race and gender differences and value congruence. In a sample of 278 restaurant employees, value congruence did moderate the relationship between race dissimilarity, gender dissimilarity and how attached an individual is to the organization. Race and gender dissimilarity had less of an effect on commitment and turnover if the values of the person were congruent with those of the organization.

This need to fit in or attach to an organization might actually be more pronounced than expected. That is, Hewlin, Dumas \& Burnett (2017) found that employees actually pretend to fit in when their values don't match those of the organization or its management. They refer to this as facades of conformity created by employees to appear that they embrace the values of the organization (Hewlin, 2003).

Similar relationships can be explored at the individual level. That is, it is important to compare values or sets of values between individuals because as social beings individuals have a need to interact with those that are similar, and the supervisor/employee relationship provides the opportunity for positive individual and organizational outcomes to be achieved when they share similar values (Meglino, Ravlin, \& Adkins, 1992). To illustrate, research indicates that value congruence between employees and their supervisor is a significant predictor of employee satisfaction and commitment (Adkins \& Naumann, 2002; Meglino, Ravlin \& Adkins, 1989), supervisory ratings of employees (Senger, 1971), and supervisor consideration and competence (Weiss, 1978). Interestingly, Bandura (1977) suggested that interpersonal value congruence may also be an important factor in changing people's behavior as they encounter others while engaging in daily activities. That is, when a supervisor and subordinate dyad share similar values, they are thought to classify and process information in similar ways (Meglino \& Ravlin, 
1998; Schein, 1985). The result may be a greater commonality in the perceptions and behaviors they display which can lead to improved interpersonal communication and the ability to more accurately predict the behavior of others (Byrne, 1971; Meglino \& Ravlin, 1998; Tafvelin, Schwarz \& Hasson, 2017). Furthermore, Fisher and Gitelson (1983) suggest that predictability in interpersonal interactions encourages more efficient interactions between supervisors and employees and reduces role stress.

To date, the majority of value congruence literature has examined congruence between values of the employee and the culture of the organization. There appears to be much less research investigating how value congruence between superiors and subordinates affects attitudes, behavior, and well-being. Kristof-Brown, Zimmerman, and Johnson (2005) acknowledge there are a limited number of studies that involve dyadic relationships even though their meta-analysis did include a few studies on person-supervisor fit or value congruence (e.g., Adkins, Russel \& Werbel, 1994; Meglino, Ravlin \& Adkins, 1989; Vianen, 2000).

Interestingly, all of these studies examined value congruence in relation to job satisfaction, organizational commitment, or overall performance with very few health or wellbeing variables such as role stress studied. Given the many positive effects that value congruence has on various work attitudes, it seems important to study the link between value congruence and stress because of the potential motivational aspects that having congruence might have, as well as the notion that congruence may act as a possible coping mechanism to counter various negative aspects of the work environment (Bouckenooghe, Buelens, Fontaine $\&$ Vanderheyden, 2005). The few studies that have examined the impact of value congruence on various conceptualizations of well-being have concluded that congruence leads to fewer somatic complaints (Burke, 2001), greater perceived stress when values conflict (Bouckenooghe et al. 2005), and less burnout (Siegall \& McDonald, 2004). Furthermore, Gilbert, Winne and Sels (2011) argue that although past research on role perceptions has produced many benefits, it does not provide results pertaining to specific aspects of an individual's role that might help explain why individuals experience role stress. As a result, studies are needed that include specific role relationships (e.g., employee-supervisor, employee-customer) in predicting stress.

Thus, the primary purpose of this study is to determine whether value congruence between a supervisor and subordinate helps to reduce the perceived role stress of the employee. The supervisor-subordinate pair was selected as the focus of this study because it is an organizationally sanctioned dyadic relationship that normally requires a generous amount of interaction. A secondary purpose of this study is to investigate whether congruence on a specific value within the dyad impacts role stress. To our knowledge, very few studies have looked at specific values independently when measuring the outcomes of value congruence.

\section{Value Congruence and Role Stress}

The vast majority of research on role stress is based on the seminal work of Kahn, Wolfe, Quinn, Snoek and Rosenthal (1964) and later of Rizzo, House and Lirtzman (1970). The results of this body of research suggest that an employee's attitudes and behavior are often influenced by expectations or standards of appropriateness held by others. 
Numerous researchers combine role conflict and ambiguity using the Rizzo, House and Lirtzman's (1970) scale to form one of the most common measures of role stress. By definition, role conflict is the degree of incompatibility or incongruity between job tasks, resources, rules or policies, and other people. Role ambiguity is the degree to which clear information is lacking regarding the expectations associated with a role, methods for fulfilling known role expectations, and/or the consequences of role performance (Kahn, Wolfe, Quinn, Snoek \& Rosenthal, 1964; Van Sell, Brief \& Schuler, 1981). In sum, the famous "role episode" posits that an employee's behavior is often influenced by expectations or standards of appropriateness held by others. When expectations are not clear or seem conflicting to the employee, the result may be role stress.

Both organizational and individual factors have been associated with role stress. Research has shown that role stress affects a number of organizational outcomes such as organizational commitment, citizenship behaviors, job satisfaction, and turnover intentions (e.g., Das, 2011 review; Fisher \& Gitelson, 1983; Jackson \& Schuler, 1985; Smith, 2010; Srivastave \& Srivastava, 2009; Yousef, 2002). Role stress has also been associated with individual aspects of well-being such as burnout (Ashill \& Rod, 2011), anxiety (Jackson \& Schuler, 1985), depression (Beehr, 1998), and somatic complaints (Ganster \& Schaubroeck, 1991; Sagiv \& Schwartz, 2000).

As Gilbert et al. (2011) point out, research is needed that examines specific aspects of roles that may lead to stress, as well as studies that include specific role relationships such as employee-supervisor dyads. One factor that may enhance one's attitudes towards work and help reduce role stress is sharing the same values as those in authority positions. Early research suggests that individuals who hold the same values are thought to share certain aspects of cognitive processing. These similarities are presumed to foster comparable methods of categorizing and interpreting environmental events, a greater commonality in perceptions and behaviors, as well as a common system of communication (Schein, 1985). That is, if two persons categorize events, objects, and concepts in similar ways, they should be able to communicate more effectively. This notion is supported in past research by Triandis (1959, 1960) who found that the greater the value similarity, the greater the communication effectiveness in a dyad. Such qualities are essential to the success of interpersonal activities because they reduce or eliminate uncertainty, stimulus overload, role stress and other negative features of work interactions (Schein, 1985). Similarly, Sagiv and Schwartz (2000) suggest that congruence between an employee's values and their manager's values promotes a positive sense of well-being which, among other things, fosters motivation to reach goals and perform better.

Why might value incongruence have an effect on well-being? Kluckhohn (1951) and Sagiv and Schwartz (2000) suggest social sanctions as a possible mechanism. That is, when people in a work environment share values, they are likely to communicate more clearly the beliefs and behaviors that are acceptable. Those who reject the prevailing norms are often ignored or punished, which is likely to produce internal conflict and negatively affect their sense of well-being. Thus, individuals engage in value consistent behavior to avoid negative feelings.

Based on the role theory and value congruence research discussed above, when a supervisor and subordinate share similar values, they engage in better interpersonal 
communication. Because supervisors are in a position to coach subordinates in proper role management by clearly defining roles and expectations, the enhanced interpersonal communication that comes from value congruence may help subordinates experience lower levels of role stress (Pearce, 1981). Thus, the following hypotheses are proposed:

H1: There will be a negative relationship between congruence in a supervisorsubordinate dyad on the achievement/working hard value and perceived role stress by the subordinate.

H2: There will be a negative relationship between congruence in a supervisorsubordinate dyad on the concern for/helping others value and perceived role stress by the subordinate.

H3: There will be a negative relationship between congruence in a supervisorsubordinate dyad on the fairness value and perceived role stress by the subordinate. H4: There will be a negative relationship between congruence in a supervisorsubordinate dyad on the honesty/integrity value and perceived role stress by the subordinate.

\section{Sample}

\section{Methods}

The present study sampled 204 full-time employees of a manufacturing corporation located in the Midwest. Of the 204 subjects that received questionnaires, 149 completed and returned usable surveys to the researcher, resulting in a response rate of $73 \%$. Out of the 149 respondents, 96 superior-subordinate dyads were matched. Thus, the sample size for this study was 96 superior-subordinate dyads.

In order to ensure an appropriate level of statistical power for the study, the required sample size was determined using Cohen's power analysis procedure (Cohen \& Cohen, 1983). The power of a statistical test is the probability that the test will detect an effect in a sample when, in fact, a true effect exists in the population (Aiken \& West, 1991). Using a target power of .80 and an effect size of .4 with an alpha of .05 , the estimated sample size for the study was 99. Therefore, the sample of 96 dyads should be satisfactory.

The age of respondents in the full sample (supervisors and subordinates) ranged from 21 to 59 years and tenure with the organization ranged from less than one year to more than ten years. Ninety-percent of the subordinates were male and $63 \%$ of the supervisors were male. Overall, $98 \%$ of the respondents selected Caucasian as their ethnic category. Sixty-two percent of the supervisor respondents had a Bachelor's degree and $20 \%$ had done some graduate work. Twenty-five percent of the subordinates had a high school degree and 16\% had a bachelor's degree.

\section{Procedure}

The Human Resources Director provided the researcher with a list of the names of fulltime employees and an organization chart that indicated superior-subordinate positions. All fulltime employees were administered a survey questionnaire containing measures of demographics, work values, and role stress. A paper copy of the survey, along with a letter of support from the President of the firm, was distributed to employees through interoffice mail. Additionally, subjects were informed that their decision to participate in the study would be completely 
voluntary and that individual responses would be seen by an outside researcher only and held in strict confidence. Respondents were asked to supply their names in order for the researcher to identify superior-subordinate dyads. Subjects completed the questionnaire and returned it in a sealed envelope to a locked container in the main lobby of the firm. The main lobby as a location for the locked container was deliberately selected because of its universal use by all employees. The questionnaires were collected by the researcher daily.

\section{Measures}

Two objectives guided measurement based on McGrath's (1986) recommendation for studying work groups. First, data was collected from multiple sources. Each subordinate and superior in a dyad completed the questionnaire. Thus, independent, multiple sources of measures were collected. Second, in the absence of multiple measures for each construct, an effort was made to control qualitatively for method bias in this study. This involved not providing information on the specific objectives of the research to respondents, negative ordering of some of the items, random structuring of scales within the questionnaire, and assuring confidentiality of responses. Study measures were generated through established measurement scales for each of the variables.

Demographics. Subjects were asked to respond to questions assessing gender, age, education, years with the company, years in current position, and race. Along with providing descriptive information, these demographic items were tested as controls for personal characteristics that may influence the dependent variable.

Role Stress. Role conflict and role ambiguity scales developed by Rizzo et al. (1970) were used in this study. These scales employ a response format that utilizes a 5-point Likert scale. Results are summed and divided by 14 to arrive at a summary indicator of role stress. Several items are negatively phrased and reverse scored in an effort to reduce response bias. The Rizzo et al. (1970) scales were selected based on previous evidence of their reliability, their factorial independence, and their extensive use in other studies (Van Sell et al., 1981). Reliabilities for role stress ranged from .78 to .82 . Sample questions used to measure role stress include: "I have to do things that should be done differently under different conditions," "I receive an assignment without the manpower to complete it," "I work on unnecessary things," " I have clear, planned goals and objectives for my job," and "I know what my responsibilities are."

Work Values. Were measured using Meglino and Ravlin's (1986) Comparative Emphasis Scale (CES). The CES measures four work values: achievement, helping/concern for others, fairness, and honesty/integrity and contains 24 pairs of different behavioral statements that were matched to control for gender bias, social desirability, and the extent to which each statement represents its specific value. For each pair of statements, respondents are asked to choose the behavior that they feel should receive the greater emphasis. In other words, the CES examines the importance of a given value relative to the other values.

The pairings of behavioral statements are arranged on the CES so that statements representing each particular value are matched with statements representing each of the other three values four times. Therefore, each value is represented on the instrument 12 times. A 
respondent receives 1 point for each value every time a statement representing that value is chosen in each of the pairs. The score for each value is calculated by summing the number of points assigned to that particular value. The maximum score for any particular value is 12 , and the total score for all four values must equal 24. An example of questions from the CES along with the value that each statement represents is as follows:

- Taking care of all loose ends on a job or project (Achievement)

- Being impartial in dealing with others (Fairness)

- Taking actions which represent your true feelings (Honesty/Integrity)

- Trying to avoid hurting other people (Concern for/Helping Others).

The authors of the CES indicate that validity is enhanced when the respondents are instructed to reflect on their previous behavior when answering questions on the scale. In addition, they went through a rigorous process where they administered the scale repeated times to examine the reliability and validity of the scale. The CES has been used in values research most often to create profiles of the four values between two individuals (i.e., supervisor and employee) to assess incongruence. It also assesses how individuals arrange values in a hierarchy because one has to choose among values that are equally desirable. As a profile measure, the CES has been found to relate to important organizational actions such as decision making, ratings of performance, satisfaction, commitment, and job choice (Adkins, Russell \& Werbel, 1994; Judge \& Bretz, 1994; Adkins \& Naumann, 2002).

For a detailed description of the development and use of the CES, see Ravlin \& Meglino (1987), Meglino, Ravlin \& Adkins, 1989; Ravlin \& Meglino, 1989; Meglino \& Ravlin 1998).

Value Congruence (VC). Value congruence between a supervisor and subordinate can be operationalized by obtaining employee perceptions of how well their values align with their supervisor's values (e.g., Kristof, 1996). An alternative, and the one used in this study, is actual or objective value congruence and is assessed by calculating the differences between supervisor and subordinate self-reported value choices using the CES.

Value congruence scores were calculated for each survey respondent by summing the total number of times they selected each one of the four values in a pair. This measure of value congruence for any of the four work values measured in the CES (achievement, concern, fairness, and honesty) can take a value from 0 to 12 while meeting the constraints that the total of all 4 must equal 24. The means and standard deviations for the four CES value scores were: achievement, $\mathrm{M}=5.2(\mathrm{SD}=2.1)$; concern and helping, $\mathrm{M}=6.6(\mathrm{SD}=2.6)$; fairness, $\mathrm{M}=6.5$ $(\mathrm{SD}=2.2)$, and honesty, $\mathrm{M}=5.7(\mathrm{SD}=2.0)$. These results are very similar to the means and standard deviations found for the four same CES measures of value congruence by Meglino, Ravlin \& Adkins (1992) in a similar sample.

More specifically, in these analyses, value congruence (VC) was calculated by taking the absolute value of the difference between the supervisor and subordinate and then squaring it for each of the four value types: achievement, concern, fairness, and honesty (Meglino, Ravlin \& Adkins; 1992). This method, while complex, allowed for examination of the impact of unit value differences (i.e., whether larger differences have proportionally greater impact than smaller 
differences), on the outcome of interest, perceived role stress. This method was used by Meglino, Ravlin, and Adkins (1992) and is also similar to the method used by Cronbach and Gleser (1953) to create the $\mathrm{D}^{2}$ index of profile dissimilarity. Because indexes were calculated using absolute value differences, they did not address whether the supervisor or subordinate had a higher score. Research has shown, however, that directional differences are not relevant to the psychological processes thought to underlie value congruence (Schein, 1985). Also examined was the correlation of rank ordering of all four CES measures for the supervisor and subordinate, and the results did not have a significant impact on role stress.

Initiating Structure and Consideration. The supervisor/manager has the essential role of creating and facilitating conditions at work so the employee can perform well and fulfill their organizational roles. A key factor in enhancing or detracting from the quality of the supervisor/subordinate relationship can be attributed to the leadership style of the manager. Of particular interest in this study was whether value congruence explained additional variance over and above the manager's leadership style. Thus, two leadership styles that have remained prominent and influential over the years, initiating structure and consideration, were included as control variables (Stodgill, 1963). While other leadership styles have been the target of much of the research over the last several years (Bass, 1990), researchers argue that initiating structure and consideration should continue to be studied (Keller, 2006; Judge, Piccolo, and Ilies, 2004). These two leadership styles have been used to enhance the psychological state of employees and thus produce positive attitudes and behaviors (Likert and Likert, 1976; Teas and Horrell, 1981; Yukl, 1981; Zahra, 1984).

Past research supports the notion that value congruence between a supervisor and employee is an underlying mechanism in the effectiveness of a leader (Burns, 1978; Conger \& Kanungo, 1987; House, 1977). Similarly, value congruence between a leader and follower has been a key factor in explaining leadership style and the leadership process in recent research studies (e.g., Jung \& Avolio, 2000; Brown \& Trevino, 2009; Hayibor, Agle, Sears, Sonnenfeld, \& Ward, 2011; Hoffman, Bynum, Riccolo, \& Sutton, 2011).

Both initiating structure and consideration were included in the study because each represents different leader behaviors. Specifically, initiating structure clarifies role expectations, role priorities, methods to evaluate performance and paths to goal attainment (Jackson \& Schuler, 1985, Sims \& Szilagyi, 1975). These clarifications and guidelines for action can be expected to reduce role stress (Kahn, Wolfe, Quinn, Snoek, \& Rosenthal, 1964; Lee and Schuler, 1980). In addition, findings from leadership research suggests that leader consideration serves an instrumental role in reducing role stress (Pearce, 1981). Supervisory consideration usually involves some degree of employee communication and interaction that provides them the opportunity to discuss and resolve conflicts. When employees are consulted about important matters that affect the success of the organization, this often reduces stress and conflicts (Bass, 1990).

The initiating structure and consideration subscales from the Leader Behavior Description Questionnaire (LBDQ) were used to measure leadership style. With the initiating structure and consideration subscales, the subordinates are asked to rate the behavior of the superior on a five-point scale. The average sum of the item responses relating to each subscale 
provides the scores for each. The estimated Cronbach's alpha reliabilities of these two subscales are .93 and .86. Sample questions measuring consideration include: "My supervisor helps make my job more pleasant." "My supervisor is friendly and approachable." "My supervisor treats all people as equals." Sample questions measuring supervisor initiating structure include: "My supervisor maintains definite standards of performance," and "My supervisor asks that the work unit members follow standard rules and regulations."

\section{Results}

Correlations among the variables, means, and standard deviations are reported in Table 1; reliability (Cronbach's alpha) is reported on the diagonal where appropriate. "The value congruence measure, CES, uses a forced-choice format, contains specific behavioral incidents that were independently judged to eliminate ambiguity, and uses a measurement technique that is substantially different from those used to measure the other constructs in this study" (Meglino, Ravline \& Adkins, 1989). Therefore, the results are not likely to have been affected to any great degree by systematic variance due to response sets (Cronbach, 1946, 1950) or common methods (Campbell \& Fiske, 1959).

As expected, both leadership styles, initiating structure and consideration, were negatively correlated with role stress. When the supervisor exhibits either leadership style, the role stress experienced by the employee is less. In addition, the hypothesized negative linkage between value congruence and role stress was significantly supported for the achievement value.

Table 1

Descriptive Statistics and Correlations

\begin{tabular}{l|rrr|c|c|c|c|c|c|c}
\hline \multicolumn{1}{c}{ Variable } & \multicolumn{1}{c}{ M } & Sd & $\mathbf{1}$ & $\mathbf{2}$ & $\mathbf{3}$ & $\mathbf{4}$ & $\mathbf{5}$ & $\mathbf{6}$ & $\mathbf{7}$ & $\mathbf{8}$ \\
\hline 1. Current position > 10 yrs & 0.11 & 0.32 & & & & & & & \\
2. Role stress & 35.72 & 7.04 & $-.221^{*}$ & $(.84)$ & & & & & \\
3. Supervisor structure & 17.60 & 3.80 & -.099 & $-.302^{* *}$ & $(.76)$ & & & & \\
4. Supervisor consideration & 23.00 & 4.80 & .056 & $-.425^{* *}$ & $.437^{* *}$ & $(.90)$ & & & \\
5. Achievement VC $($ diff & ) & 7.40 & 10.00 & .070 & $.199^{*}$ & -.038 & -.066 & & & \\
6. Concern VC $\left(\right.$ diff $\left.^{2}\right)$ & 12.00 & 13.50 & -.099 & .065 & .133 & -.187 & .053 & & \\
7. Fairness VC $\left(\right.$ diff $\left.^{2}\right)$ & 10.10 & 13.20 & .086 & -.097 & .193 & .113 & .105 & .041 & \\
8. Honesty VC $\left(\right.$ diff $\left.^{2}\right)$ & 8.90 & 12.10 & -.150 & .116 & -.146 & -.035 & -.088 & .055 & .165 \\
\hline
\end{tabular}

$*=\mathrm{p}<.05 * *=\mathrm{p}<.01$

That is, the higher the level of squared difference in achievement value, the higher the role stress experienced.

Hierarchical least squares regression was used to test for the effect of all four individual CES value congruence measures as well as the total of all four on role stress (SAS, v9.3; SAS Institute Inc., Cary, NC, USA.). The results are reported in Table 2 for achievement value congruence and Table 3 for the remaining three value congruence measures: consideration and helping, fairness, honesty, and the overall total. As highlighted in Model 1, the control variable of subordinate years in current position (in current position for ten or more years) $(p<0.05)$ accounted for the initial $3.91 \%$ in variance. After controlling for years in current position, Model 
2, which controls for supervisor structure $(p<0.01)$, explained 9.83\% additional variance in role stress. In Model 3, supervisor consideration $(p<0.01)$ explained an additional $8.33 \%$ variance in role stress. Model 4 shows that after controlling for these three variables, the difference in achievement congruence $(p<0.05)$ (difference between supervisor and subordinate ${ }^{2}$ ) accounts for an additional $2.79 \%$ of the variance in role stress.

Table 2

Regression of Role Stress on Demographics Supervisor Traits, and Achievement

\begin{tabular}{lcccc}
\hline Variable & Model 1 & Model 2 & Model 3 & Model 4 \\
\hline Current position > 10 yrs & $-4.91^{*}$ & $-5.63^{* *}$ & $-4.88^{* *}$ & $-5.20^{* *}$ \\
Supervisor structure & & $-0.61^{* *}$ & $-0.33^{*}$ & $-0.33^{*}$ \\
Supervisor consideration & & & $-0.49^{* *}$ & $-0.47^{* *}$ \\
Achievement VC (diff2) & & & & $0.13^{*}$ \\
Constant & $36.28^{* *}$ & $47.12^{* *}$ & $53.34^{* *}$ & $52.00^{* *}$ \\
& & & & \\
R2 & 3.91 & 13.74 & 22.07 & 24.88 \\
DR2 & & $9.83^{* *}$ & $8.33^{* *}$ & $2.79^{*}$ \\
\hline
\end{tabular}

$*=\mathrm{p}<.05^{* *}=\mathrm{p}<.01$

Table 3

Regression of Role Stress on Demographics Supervisor Traits, and Consideration, Fairness, Honesty, and Total VC

\begin{tabular}{|c|c|c|c|c|}
\hline Variable & Model4b & Model4c & Model4d & Model4d \\
\hline Current position $>10 y r s$ & $-4.88^{*}$ & $-4.87^{*}$ & $-4.71^{*}$ & $-4.83^{*}$ \\
\hline Supervisor structure & -0.33 & -0.33 & -0.32 & -0.36 \\
\hline Supervisor consideration & $-0.49^{* *}$ & $-0.49^{* *}$ & $-0.49^{* *}$ & $-0.47^{* *}$ \\
\hline Concern VC( $\left.\operatorname{diff}^{2}\right)$ & 0 & & & \\
\hline Fairness VC $\left(\operatorname{diff}^{2}\right)$ & & 0 & & \\
\hline Honesty VC $\left(\operatorname{diff}^{2}\right)$ & & & 0.03 & \\
\hline Total all 4 VC types & & & & 0.02 \\
\hline Constant & $53.30^{* *}$ & $53.33^{* *}$ & $52.87^{* *}$ & $52.40^{* *}$ \\
\hline $\mathrm{R}^{2}$ & 21.23 & 21.24 & 21.46 & 22.09 \\
\hline
\end{tabular}

There are significant correlations between some of the independent variables; (e.g., supervisor consideration and supervisor structure), used as independent variables. Each variable was tested and all resulted in a variance inflation factor (VIF) significantly below 10; the limit most frequently suggested in the methodology literature (e.g., Kennedy, 1992; Marquardt, 1970; Neter, Wasserman, \& Kutner, 1989)

Numerous other variables were tested for significance in contributing to explaining the variance in role stress. No other variables had a significant impact on subordinate role stress. 
Some other variables (e.g., other demographics) could not be used as the level of multicollinearity among them was far too high.

The results support Hypothesis 1 regarding the impact of achievement value congruence on role stress. Interestingly, individuals who are 26 to 35 years of age experience significantly more role stress, while those having more than 10 years in their current position experience decreased role stress. Achievement value congruence further decreases role stress significantly. All other value congruence measures were tested and none had a significant impact on role stress. Thus, there was not support for Hypothesis 2 (concern for/helping others), Hypothesis 3 (fairness), and Hypothesis 4 (honesty/integrity).

Meglino, Ravlin, and Adkins (1992) used only the achievement value measure in their examination of plant production employees. The sample in this current study is very similar; it is from a manufacturing facility located in the Midwest and achievement seemed to be the most relevant of the four CES value congruence measures because of the working environment in the plant. In part, this may explain why the current study also found only the achievement value congruence from the CES scale to have a significant impact on subordinate role stress.

The control variables, subordinate years in current position (in current position for ten or more years), supervisor consideration, and supervisor initiating structure, all had significant effects in the hypothesized direction.

\section{Discussion}

The main purpose of this study was to investigate the impact that value congruence in a supervisor-subordinate dyad has on the role stress of subordinates. The four work values measured in the CES were achievement, concern, fairness, and honesty. However, the expected negative linkage between value congruence and role stress was significantly supported for only the achievement value. One explanation for this finding may be related to the demographics of the sample in this study. The participants in this study were employed with a United States based company, and $98 \%$ of the respondents indicated that their ethnic category was Caucasian. According to Hofstede (2001), workers in the United States tend to have a high achievement orientation or a cross-cultural preference describing the degree to which people in a culture emphasize competitive versus cooperative relations with other people. In contrast, people who are in nurturing-oriented cultures emphasize relationships and the well-being of others. They focus on interpersonal interactions and caring rather than competition and personal success. Three of the values measured on the CES, concern, fairness, and honesty, describe values that may be more typical in nurturing-oriented cultures. These three values may actually be shared assumptions in the culture of this organization rather than shared values. Shared assumptions are subconscious, taken-for-granted perceptions of the correct way to think and behave (Ashkanasy, 2003). Shared assumptions are so deeply ingrained that they would unlikely be discovered by simply surveying employees. Rather, these assumption would rise to the surface and become apparent only by observing the employees, analyzing their decisions, and debriefing them on their actions. 
The sample in this study consisted of supervisors and subordinates employed in a manufacturing organization where processes and procedures are aimed toward achieving production goals and efficiencies or a more achievement-oriented environment. Clearly, having congruent achievement values in this type of organization makes sense.

Recently, Brown \& Trevino (2009) found "type of occupation" influences supervisor and employee values significantly in their study of nurses and nurse managers. Moreover, they suggest that future studies of supervisor-subordinate value congruence should incorporate an occupation-based dimension since values in some occupations are inherent in the role and difficult to change. Similarly, Holland (1997) notes that research on careers supports the notion that individuals often choose careers based on fairly stable personal values, and these values are supported and reinforced by organizational socialization and training experiences.

Since values guide our preferences for outcomes or courses of action in a variety of situations, in an achievement oriented culture, a superior may be expected to provide clear goal expectations and ample work information to the subordinate in order for them to better compete, thus resulting in less role stress.

It is also expected that some of the demographic variables included in this study as controls such as gender and number of years in the organization might reflect differences in values. For example, the sample consisted of more males than females and more males are in supervisory positions (63\%). As a result, it is quite likely that males in a manufacturing environment would be more achievement-oriented (e.g., see Schein, 1985). It is also not surprising that those employed with the organization greater than 10 years experienced less role stress. Newcomers to organizations often experience stress and uncertainty early in their tenure, and gradually adjust through socialization and building strong relationships with supervisors and co-workers (Bravo, Peiro, Rodriguez, \& Whitely, 2003).

This study, like most, had some limitations. One potential limitation is the sample size. While there was an overall response rate of $73 \%$, the respondents had to be matched into superior-subordinate dyads. If one member of the dyad did not respond, then the survey of the responding member was not usable. Due to the need to match respondents into dyads, a sample size of 96 dyads was obtained. Although this size had the statistical power estimated for the analyses conducted, more data points would have been preferable.

A second potential limitation is that certain elements of the study may have skewed the results. For example, respondents were asked to put their names on the survey in order for the researcher to match superior-subordinate dyads. Even though participants were reassured that their responses would be confidential and that participation in the study was voluntary, they may have felt they should participate because of the strong encouragement from top management. This, in turn, may have resulted in respondents answering surveys just to show participation without thoroughly and carefully thinking about their answers to the questions. Also, respondents who had poor relationships with their superior may have elected not to participate in the study. 
A possible third limitation involves past research that supports the notion that achieving value congruence might be challenging because values are often stable and can be related to the occupations people choose (e.g., see Brown \& Trevino, 2009; Spokane, 1985). Interestingly though, in a similar sample to ours (i.e., workers in a manufacturing plant), Meglino, Ravlin \& Adkins (1989) found that the values of the workers and their supervisors didn't change much over time. In fact, having value congruence with their supervisor enhanced commitment to the organization over a period of time. Nevertheless, this may not apply to all organizations, and it is important to note that different organizations might have more or less opportunities for interactions between supervisors and subordinates which could affect the results.

A fourth potential limitation of the study lies in the educational level of the subordinates in the sample. Twenty-five percent of subordinates reported that their highest level of education was a high school degree, and 16\% reported having a bachelor's degree. With the relatively low level of education, there may be concern about the ability of the respondents to clearly understand the instructions and information regarding the study. While there were no anomalies in responses which may indicate that subordinates did not understand the instructions, nor were there questions about the survey, the educational demographics of the sample is a limitation.

It is also possible that some employees left the organization over time if their values did not match their supervisor's. Consequently, extreme cases of value incongruence were not detected. However, leaving the organization due to dissatisfaction of any kind is present in all samples of employed individuals. The only way it could be corrected would be to collect data on those who left and those who stayed. This would allow a calculation of a sample selection bias correction. Unfortunately, this type of information is extremely difficult to obtain and is not included in most organizational research.

A final caveat concerns limitations relevant to the design of the study. The existence of mono-method bias may be present since all data was collected through a questionnaire format. Also, the study suffers from lack of control by the researcher and noise in the study setting both of which are inherent limitations in this type of research design.

Future research might improve on the current study by including measures of communication and interpersonal skill levels in the questionnaire. These measures will assist the researcher in assessing the level of communication and interpersonal skills that the respondent possesses at the time of the study. Thus, the researcher can determine whether these variables are influencing the impact of value congruence on various outcome variables. Additionally, although it is the values of the workers and their supervisors that are of particular interest, future research might also consider the role of value congruence in organizations where "strong" cultures are present. It is quite possible that such cultural forces may produce similarities in the work values of individual employees. Finally, occupational context appears to be strongly related to individual's values. That is, if the value congruence between supervisor and subordinate is lacking, it is quite possible that the employee's values are more aligned to her/his occupation rather than being influenced by the supervisor. To illustrate Brown and Trevino (2009) studied whether employee occupation plays a role in charismatic leaders achieving value congruence with their followers. Holland (1997) suggests that individuals often choose careers based on stable personal values. This is exactly what Brown and Trevino (2009) found in the 
healthcare industry. Nurses had stronger self-transcendence and conservation values than did those who work in administrative positions, but weaker openness to change and selfenhancement values. Thus, the study of value congruence at multiple levels of the organization will help develop a better understanding of how value congruence differs among various industries and occupations.

This study offers several implications for organizations. First, it goes without saying that the health and well-being of employees is important to all organizations, and too much stress at work has the potential to have negative consequences for the individual (i.e., depression, burnout) and the organization (i.e., absenteeism, turnover). Our findings suggest that having congruence on the achievement value appears to be an important factor in reducing the role stress that individuals experience. This is especially true in organizations where processes and procedures are aimed at achieving production goals. From a job design perspective, when both the supervisor and subordinate value achievement or have high achievement needs, the supervisor is more likely to provide additional opportunities for employees to be successful in their roles by setting challenging, yet attainable goals, and rewarding goal achievement. Similarly, employees may actually seek out more challenging responsibilities at work or view challenges as opportunities rather than threats.

Additional positive outcomes occur for the organization when a supervisor and subordinate share similar values. They engage in better interpersonal communication. Because supervisors are in a position to coach subordinates in proper role management by clearly defining roles and expectations, the enhanced interpersonal communication that comes from value congruence may help subordinates experience lower levels of role stress. In summary, congruence between a subordinate's values and their manager's values promotes a positive sense of well-being which, among other things, fosters motivation to reach goals and perform better. 


\section{References}

Adkins, C. L. \& Naumann, S. E. (2002). The value of achievement and responses to the work environment. Journal of Behavioral and Applied Management, 3, 141-158.

Adkins, C. L., Russel, C. J., \& Werbel, J. D. (1994). Judgments of fit in the selection process: The role of work value congruence. Personnel Psychology, 47(3), 605-623.

Aiken, L. A. \& West, S. G. (1991). Multiple regression: testing and interpreting interactions. Newbury Park, CA: Sage.

Ashill, N. J., \& Rod, M. (2011). Burnout processes in non-clinical health service encounters. Journal of Business Research, 64, 1116-1127.

Ashkanasy, N. M. (2003). The case for culture. In R. Westwood and S. Clegg (Eds.), Debating organization (pp. 300-310). Malden, MA: Blackwell.

Bandura, A. (1977). Social learning theory. Englewood Cliffs: Prentice Hall.

Bass, B. M. (1990). Bass and Stogdill's Handbook of Leadership. New York: The Free Press.

Beehr, T. A. (1998). An organizational psychology meta-model of occupational stress. In C.L. Cooper (Ed.), Theories of organizational stress (pp. 6-27). New York: Oxford University Press.

Bouckenooghe, D., Buelens, M., Fontaine, J. \& Vanderheyden, K. (2005). The prediction of stress by values and value conflict. The Journal of Psychology, 139, 369-382.

Bravo, M .J, Peiro, J. M., Rodriguez, I. \& Whitely, W. T. (2003). Social antecedents of role stress and career-enhancing strategies of newcomers to organizations: A longitudinal study. Work \& Stress, 17, 195-217.

Brown, M. E. \& Trevino, L. K. (2009). Leader-Follower values congruence: Are socialized charismatic leaders better able to achieve it? Journal of Applied Psychology, 94, 478-490.

Burke, R. (2001). Organizational values, work experiences, and satisfactions among managerial and professional women. Journal of Management Development, 20, 346-353.

Burns, J. M. (1978). Leadership. New York: Harper and Row.

Byrne, D. (1971). The attraction paradigm. New York: Academic Press.

Campbell, D. X. \& Fiske, D. W. (1959). Convergent and discriminant validation by the multitrait- multi-method matrix. Psychological Bulletin, 56, 81-105.

Chatman, J. A. (1989). Improving interactional organizational research: A model of personorganization fit. Academy of Management Review, 14, 333-349.

Cohen, J. \& Cohen, P. (1983). Applied multiple regression/correlation analysis for the behavioral sciences $\left(2^{\text {nd }}\right.$ ed.). Hillsdale, N.J.: Erlbaum.

Conger, J. A. \& Kanungo, R.N. (1987). Toward a behavioral theory of charismatic leadership in organizational settings. Academy of Management Review, 12, 637-647.

Cronbach, L. J. (1946), Response sets and test validation. Educational and Psychological Measurement, 6, 475-494.

Cronbach, L. J. (1950). Further evidence on response sets and test design. Educational and Psychological Measurement, 10, 3-31.

Cronbach, L. J., \& Gleser, G. C. (1953). Assessing similarity between profiles. Psychological bulletin, 50(6), 456.

Das, A. K. (2011). Organizational role-stress: A critical review. Social Science International, 27, 131-134. 
Dose, J. J. (1997). Work values: An integrative framework and illustrative application to organizational socialization. Journal of Occupational and Organizational Psychology, 70, 219-240.

Edwards, J. R. (1994). The study of congruence in organizational behavior research: Critique and a proposed alternative. Organizational Behavior and Human Decision Processes, 58, 51-100.

Erdogan, B., Kraimer, M. L., \& Liden, R. C. (2004). Work value congruence and intrinsic career success: the contemporary roles of leader-member exchange and perceived organizational support. Personnel Psychology, 57, 305-332.

Finegan, Joan E. (2000). The impact of person and organizational values on organizational commitment. Journal of Occupational and Organizational Psychology, 73, 149-169.

Fisher, C. D. \& Gitelson, R. (1983). A meta-analysis of the correlates of role conflict and ambiguity. Journal of Applied Psychology, 68, 320-333.

Ganster, D. C. \& Schaubroeck, J. (1991). Work stress and employee health. Journal of Management, 17, 235-271.

Gilbert, C., Winne, S. \& Sels, L. (2011). Antecedents of front-line managers' perceptions of HR role stressors. Personnel Review, 40, 549-569.

Gonzalez, J. H. (2016). Demographic dissimilarity, value congruence and workplace attachment: Asymmetrical group effects. Journal of Managerial Psychology, 31(1), 169-185.

Hayibor, S., Agle, B. R., Sears, G. J., Sonnenfeld, J. A. \& Ward, A. (2011). Value congruence and charismatic leadership in CEO-Top manager relationships: An empirical investigation. Journal of Business Ethics, 102, 237-254.

Hewlin, P. F. (2003). And the award for best actor goes to.....Facades of conformity in organizational settings. Academy of Management Review, 28, 633-642.

Hewlin, P. F., Dumas, T. L. \& Burnett (2017). To thin own self be true? Facades of conformity, values incongruence, and the moderating impact of leader integrity. Academy of Management Journal, 60(1), 178-199.

Hoffman, B. J., Bynum, B. H., Piccolo, R. F. \& Sutton, A. W. (2011). Person-organization value congruence: How transformational leaders influence work group effectiveness. Academy of Management Journal, 54, 779-796/

Hofstede, G. (2001). Culture's consequences: comparing values, behaviors, institutions, and organizations across nations. Thousand Oaks, CA: Sage.

Holland, J. F. (1997). Making vocational choices: A theory of vocational personalities and work environments ( $3^{\text {rd }}$ ed.). Odessa, FL: Psychological Assessment Resources.

House, R. J. (1977). A 1976 theory of charismatic leadership. In J. G. Hunt \& L. L. Larson (Eds.), Leadership: The cutting edge. 189-204. Carbondale IL. Southern Illinois University Press.

Jackson, S. E. \& Schuler, R. S. (1985). A meta-analysis and conceptual critique of research on role conflict and role ambiguity in work settings. Organizational Behavior and Human Decision Processes, 36, 16-78.

Judge, T. A. \& Bretz, R. D. (1994). Effects of work values on job choice decisions. Journal of Applied Psychology, 77, 261-271.

Judge, T. A., Piccolo, R., \& Ilies, R. (2004). The forgotten ones? The validity of consideration and initiating structure in leadership research. Journal of Applied Psychology, 89, 36-51. 
Jung, D. I., \& Avolio, B. J. (2000). Opening the black box: An experimental investigation of the mediating effects of trust and value congruence on transformational and transactional leadership. Journal of Organizational Behavior, 21, 949-964.

Kahn, R. L., Wolfe, D. M., Quinn, R. P., Sneok, J. D. \& Rosenthal, R. A. (1964). Organizational Stress: Studies in role conflict and ambiguity. New York: Wiley.

Keller, R. (2006). Transformational leadership, initiating structure, and substitutes for leadership: A longitudinal study of research and development project team performance. Journal of Applied Psychology, 91(1), 202-210.

Kennedy, P. (1992). A Guide to Econometrics. Oxford: Blackwell.

Kluckhohn, C. (1951). Values and value-orientation in the theory of action. In T. Parsons \& E. Shils (Eds.), Toward a general theory of action, 388-433.

Kristoff, A. (1996). Person-organization fit: An integrative review of its conceptualizations, measurement, and implications. Personnel Psychology, 49, 1-49.

Kristof-Brown, A., Zimmerman, R. \& Johnson, E. (2005). Consequences of individuals' fit at work: a meta-analysis of person-job, person-organization, person-group, and personsupervisor fit. Personnel Psychology, 58 (2), 281-342.

Lee, C. \& Schuler, R. (1980). Goal specificity and difficulty and leader initiating structure as strategies for managing role stress. Journal of Management, 6, 177-187.

Likert, R. \& Likert, J. (1976). New Ways of Managing Conflict. New York, NY: McGraw Hill Book Company.

Marquardt, D. W. (1970). Generalized inverses, ridge regression, biased linear estimation, and nonlinear estimation. Technometrics, 12, 591-256.

McGrath, J. E. (1986). Studying groups at work: Ten critical needs. In Goodman, P.S. (ed.), Designing effective work groups. San Francisco, CA: Jossey-Bass.

Meglino, B. M., Ravlin, E. C. \& Adkins, C. L. (1989). A work values approach to corporate culture: A field test of the value congruence process and its relationship to individual outcomes. Journal of Applied Psychology, 74, 424-432.

Meglino, B. M., Ravlin, E. C. \& Adkins, C. L. (1992). The measurement of work value congruence: A field study comparison. Journal of Management, 18, 33-43.

Meglino, B. M. \& Ravlin, E. C. (1986). Comparative emphasis scale. Riegel and Emory Center, University of South Carolina.

Meglino, B. M., Ravlin, E. C. (1998). Individual values in organizations: Concepts, controversies, and research. Journal of Management, 24, 351-389.

Neter, J., Wasserman, W. \& Kutner, M. H. (1989). Applied Linear Regression Models. Homewood, IL: Irwin.

Pearce, J. (1981). Bringing some clarity to role ambiguity research. Academy of Management Review, 6, 665-674.

Ravlin, E.C. \& Meglino, B.M. (1987). Effect of values on perception and decision making: A study of alternative work values measures. Journal of Applied Psychology, 72, 666-673.

Ravlin, E. C., \& Meglino, B. M. (1989). The transitivity of work values: Hierarchical preference ordering of socially desirable stimuli. Organizational behavior and human decision processes, 44(3), 494-508.

Rizzo, J. R., House, R. J., \& Lirtzman, S. I. (1970). Role conflict and ambiguity in complex organizations. Administrative Science Quarterly, 15, 160-163.

Rokeach, M. (1973). The nature of human values. New York: Free Press. 
Sagiv, L. \& Schwartz, S. (2000). Value priorities and subjective well-being. Direct relations and congruity effects. European Journal of Social Psychology, 30, 177-198.

SAS software, Version 9.3 for Windows. Copyright (C) 2013 SAS Institute Inc., Cary, NC, USA

Schein, E. H. (1985). Organizational culture and leadership. San Francisco: Jossey-Bass.

Schwartz, S. \& Bilsky, W. (1987). Toward a universal psychological structure of human values. Journal of Personality and Social Psychology, 53, 550-562.

Senger, J. (1971). Managers' perceptions of subordinates' competence as a function of personal value orientation. Academy of Management Journal, 14, 415-423.

Shea-Van Fossen, R. \& Vredenburgh, D. (2014). Exploring differences in work's meaning: An investigation of individual attributes associated with work orientations. Journal of Behavioral and Applied Management, 15, 101-120.

Siegall, M. \& McDonald, T. (2004). Person-organization value congruence, burnout and diversion of resources. Personnel Review, 33, 291-301.

Sims, H. \& Szilagyi, A. (1975). Leader structure and subordinate satisfaction for two hospital administrative levels: A path analysis approach. Journal of Applied Psychology, 60, 194197.

Smith, K. J. (2010). A structural model of teacher role stress, satisfaction, commitment, and intentions to leave: A comment on Conley and you (2009). Psychological Reports, 106.2, 576-578.

Srivastave, A. K. \& Srivastava, A. K. (2009). Organizational commitment: Relationship with occupational stress. Journal of Psychosocial Research, 4, 401-407.

Stodgill, R. (1963). Manual for the leader behavior description questionnaire - form XII. Columbus, OH: Bureau of Business Research, Ohio State University.

Spokane, A. R. (1985). A review of research on person-environment congruence in Holland's theory of careers. Journal of Vocational Behavior, 26, 306-343.

Teas, K. \& Horrell, J. (1981). Salespeople satisfaction and performance feedback. Industrial Marketing Management, 10, 49-57.

Tafvelin, S., Schwarz, U. \& Hasson, H. (2017). In agreement? Leader-team perceptual distance in organizational learning affects work performance, 75, 1-7.

Triandis, H. (1959). Cognitive similarity and interpersonal communication in industry. Journal of Applied Psychology, 43, 321-326.

Triandis, H. (1960). Cognitive similarity and communication in a dyad. Human Relations, 13, 175-183.

Van Sell, M., Brief, A. P. \& Schuler, R. S. (1981). Role conflict and role ambiguity: Integration of the literature and directions for future research. Human Relations, 34, 43-71.

Van Vianen, A.E. (2000). Person-organization fit: The match between newcomers' and recruiters' preferences for organizational cultures. Personnel Psychology, 53, 113-149.

Weiss, H. M. (1978). Social learning of work values in organizations. Journal of Applied Psychology, 63, 711-718.

Yousef, D. A. (2002). Job satisfaction as a mediator of the relationship between role stressors and organizational commitment: A study from an Arabic cultural perspective. Journal of Managerial Psychology, 17, 250-266.

Yukl, G. (1981). Leadership in Organizations. Englewood Cliffs, NJ: Prentice-Hall, Inc.

Zahra, S. (1984). Antecedents and consequences of organizational commitment: An integrative approach. Akron Business and Economic Review, 15, 26-3. 